\title{
SELEÇÃO DE FUMO "AMARELINHO" PARA ESTUFA
}
A. R. Lima,
F. G. Brieger $\left({ }^{*}\right)$ e
S. R. dos Santos

\section{GENERALIDADES}

O fumo Amarelinho do Rio Grande do Sul se apresenta como um grupo de formas ou tipos bem diferenciados, tendo em comum certos caracteres, dos quais citaremos: elevado número de fôlhas de grandes dimensões - grande vigor vegetativo - e a tendência natural de curar com coloração, ora mais, ora menos acentuada. Alguns Amarelinhos são utilizados na produção de fumo de rôlo, outros na de galpão e ainda outros na de amarelo de estufa. Êstes são os mais claros, de fôlhas mais tinas, que, ao curar, adquirem coloração amarelo-pronunciada.

Ao ser iniciada a introdução das estufas para a cura do fumo, visando a produção dêsse tabaco, "flue-cured tobacco", tipo americano, foram experimentadas as variedades americanas usadas para êste sistema de cura nos E.U.A., juntamente com outros fumos, dentre os quais, os Amarelinhos. Êstes se revelaram não sòmente capazes de produzir bom tabaco amarelo de estufa, como também possuiam maior resistência, melhor adaptação ao meio e maior produtibilidade. Isso sucedeu há cêrca de 20 anos. A partir de então fêz-se uma seleção contínua, embora não sistematizada, visando o melhoramento e criação de tipos superiores, tanto pela conformação, como pela tendência de fixar coloração amarela na cura em estufa, tendo dado ocasião ao aparecimento de diversas variedades. A respeito da origem dêsse fumo, pouco conseguimos saber. Existe há muitos anos no Rio Grande do Sul e parece ter-se originado de cruzamento entre variedades creoulas e alguma ou algumas variedades exóticas, entre as quais talvez figure o tipo "Maryland" (americano).

\section{ENSAIOS DE PROGÊNIES}

A introdução desta variedade deu-se em 1933, no Instituto Agronô. mico, tendo aquí sido registada sob o número v. 33. No mesmo ano foi providenciada a sua semeação na Fazenda Santa Elisa, para as pri-

(") Da Escola Superior de Agricultura "Luiz de Queiroz". 
meiras observações. Resultou um campo com plantas de caraterísticos vegetativos os mais variados e heterogêneos. Como apresentasse, todavia, tipos interessantes para futuros trabalhos, iniciou-se a seleção pela eleição de um certo número de plantas que, autofecundadas, foram no ano seguinte plantadas na Estação Experimental de Tupí. Após nova autofecundação, foram obtidas 180 novas progênies, cuja plantação foi efetuada na Fazenda Santa Elisa em fins de 1936 com a numeração 515 a 694.

Assim, data dêsse ano o início de um verdadeiro trabalho de seleção e melhoramento, visando a obtenção de uma variedade produtiva, uniforme e qualitativamente superior. Planejou-se a instalação de ensaios sucessivos de progênies até se conseguir, for linha pura, o tipo ou os tipos desejados.

As 180 progênies foram, portanto, plantadas em 180 fileiras, para as primeiras observações e registos. Para a verificação de uma possível resistência a qualquer das moléstias mais importantes, efetuaram-se as contagens de plantas doentes, o que, aliás, se tornou de praxe em todos os nossos ensaios posteriores. Fizeram-se anotações gerais não só sôbre desenvolvimento, conformação e caracteres vegetativos, como também sôbre as qualidades das fôlhas curadas. Todos os dados foram registados, para permitir a eleição dos tipos requeridos.

O seguinte fato, que forneceu uma diferenciação básica para início dos trabalhos, foi notado nas observações sôbre conformação das plantas: um orupo de plantas possuia folhas largas e erectas, e, um outro, fôlhas estreitas e recurvadas, pelo que foi possível classificar os indivíduos, de acôrdo com a forma ou o hábito de suas fôlhas em relação à planta. Foram convencionados 6 tipos, $A, B, C, D, E$ e F. Nos dois primeiros, incluiram-se as plantas de fôlhas largas e erectas, e, nos restantes, as de fôlhas recurvadas e pendentes. Outras diferenças em altura, número e coloração das fôlhas, caraterizavam os tipos entre si.

Obtidos e anotados todos os dados julgados necessários, procedeu-se à autofecundação de tôdas as plantas medidas, e pela seleção das melhores chegou-se ao ano seguinte com 200 novas progênies, para o prosseguimento da experiencia. Estas foram conseguidas de 61 das 180 originais.

ensaio continuou em 1937-38, obedecendo ao mesmo critério, e assim sucessivamente até a plantação de 1941-42, quando se julgou conveniente dar por findos os trabalhos, com a fixação e uniformização de certos tipos razoàvelmente bons.

Voltando, entretanto, aos 6 tipos convencionados, de conformação vegetativa, daremos uma idéia de como se procedeu à seleção, em relação 
a êles. Verificou-se que, dentro dos dois tipos principais, "fôlhas erectas" e "fôlhas recurvadas", as diferenças entre maior ou menor altura, maior ou menor número de fôlhas, coloração mais ou menos clara, etc., que originalmente serviram para a classificação dos tipos designados por letras, não se mantiveram através das gerações, ou melhor não passaram de variações ou flutuações vegetativas anuais, sob a ação de diferenças de fertilidade do terreno, épocas de transplante, espaçamento, etc. Dêste modo, separaram-se, morfològicamente, dois tipos, com os seguintes caraterísticos :

\section{Tipo A}

Fôlhas erectas e largas

Coloração verde

Altura média

Ciclo mais longo

Textura média

Internódios curtos

(Reunindo $A$ e $B$ )
Tipo D

Fôlhas recurvadas e estreitas

Coloração verde-clara

Altura elevada

Ciclo mais curto

Textura fina

Internódios longos

(Reunindo C, D, E e F).

Foi sòmente na plantação de 1940-4l que se separaram definitivamente os tipos " $A$ " e " $D$ " em duas variedades distintas. Ao primeiro se filiaram as progênies de 0-200 a $0-318 \mathrm{e}$, ao segundo, de 0-001 a 0-199. Manteve-se para o primeiro grupo o registo original, v. 33, e, para o outro, deu-se um novo, v. 380, que foi batizado sob o nome de "Amarelinho Tietê", visto todo o trabalho de seleção, ter-se efetuado na Estação Experimental de Tietê.

A variedade 33 ou tipo " $\mathrm{A}$ ", com qualidades mais adequadas para fumo de galpão, foi retirada do conjunto original, mantendo-se o ensaio apenas com a V. 380 para a obtenção de um bom fumo para estufa.

Das 180 progênies originais de 1936-37, apenas 3 foram mantidas no ensaio, tendo sido eliminadas as restantes, nas seleções, com exceção de 29 que foram separadas como V. 33 (tipo A). Em 1937-38 fêz-se uma eleição adicional, em Tietê e Tupí, de belas plantas tipo D, da mesma variedade, as quais foram incorporadas ao ensaio, como 2 conjuntos, que mais tarde foram denominados linhagens "Tietê" e "Tupi".

$O$ ensaio foi levado a têrmo com 5 linhagens, às quais se filiaram tôdas as suas progênies 1941-42; destas, 3 são as 569, 612 e 627, 1936-37 e duas são as "Tietê" e Tupí, 1937-38.

Daremos adiante o "pedigree" das progênies obtidas em 1942, devendo-se observar que no esquema estão excluídas as 1939-40, para não aumentarem desnecessàriamente o tamanho do quadro, e as 1940-41, que foram perdidas. 
"Pedigree" das progénies obtidas em 1942, partindo das cinco linhagens originais, $569,612,627$, "Tietê" e "Tupi". No esquema estão excluidas as familias pertencentes co ano de 1939-40.

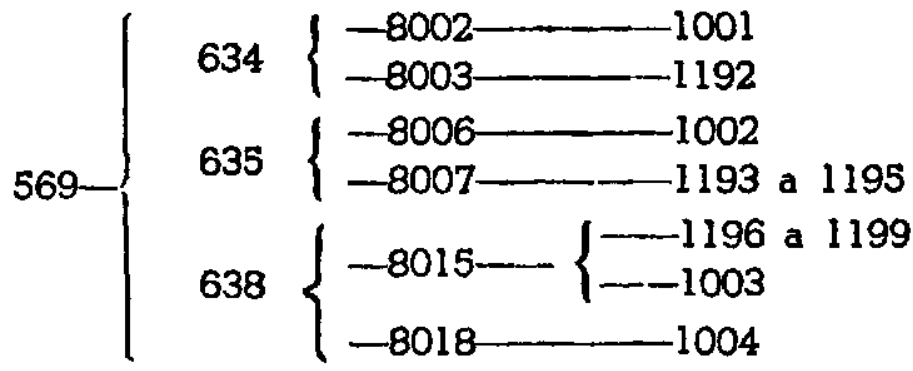

$717\left\{\begin{array}{l}-8069-1006 \\ -8071-1007 \text { a } 1009 \\ -8072-1010 \\ -8073-1012 \text { a } 1013 \\ -8074-1125 \text { a } 1126\end{array}\right.$

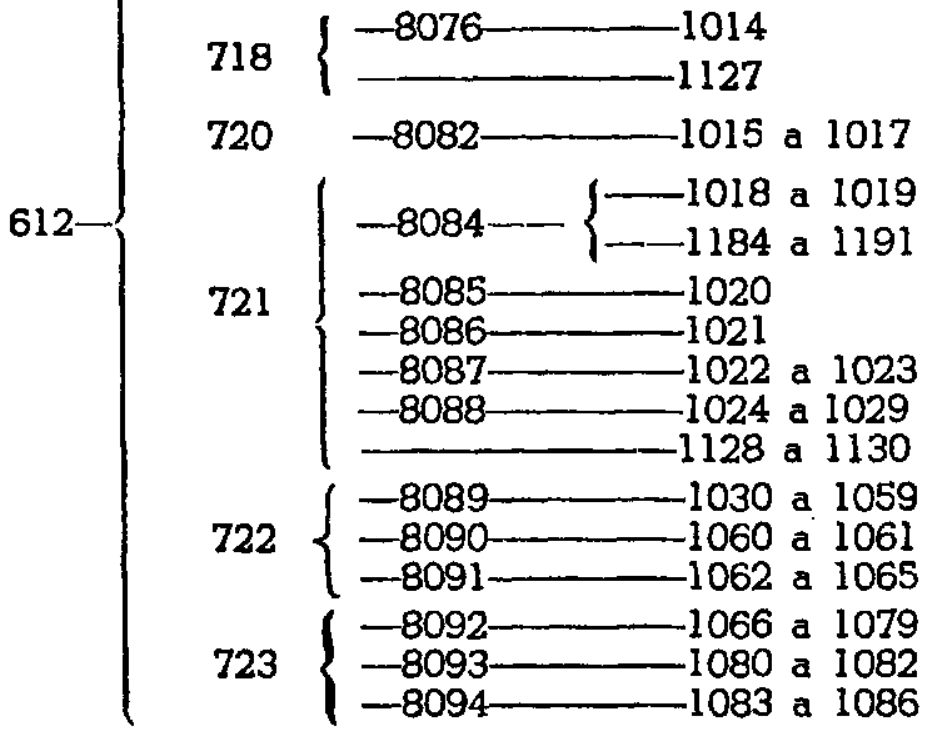

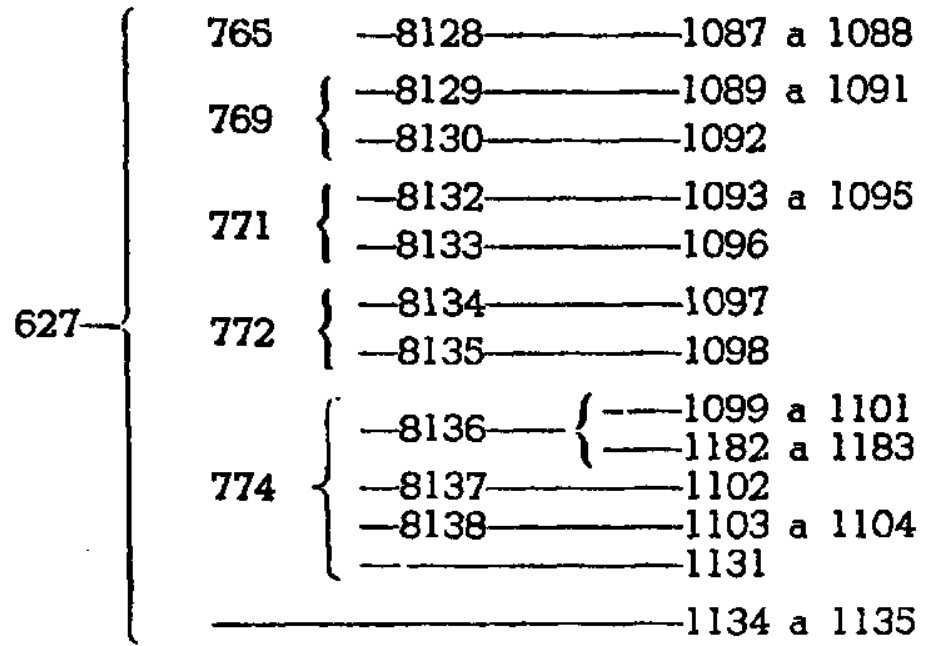




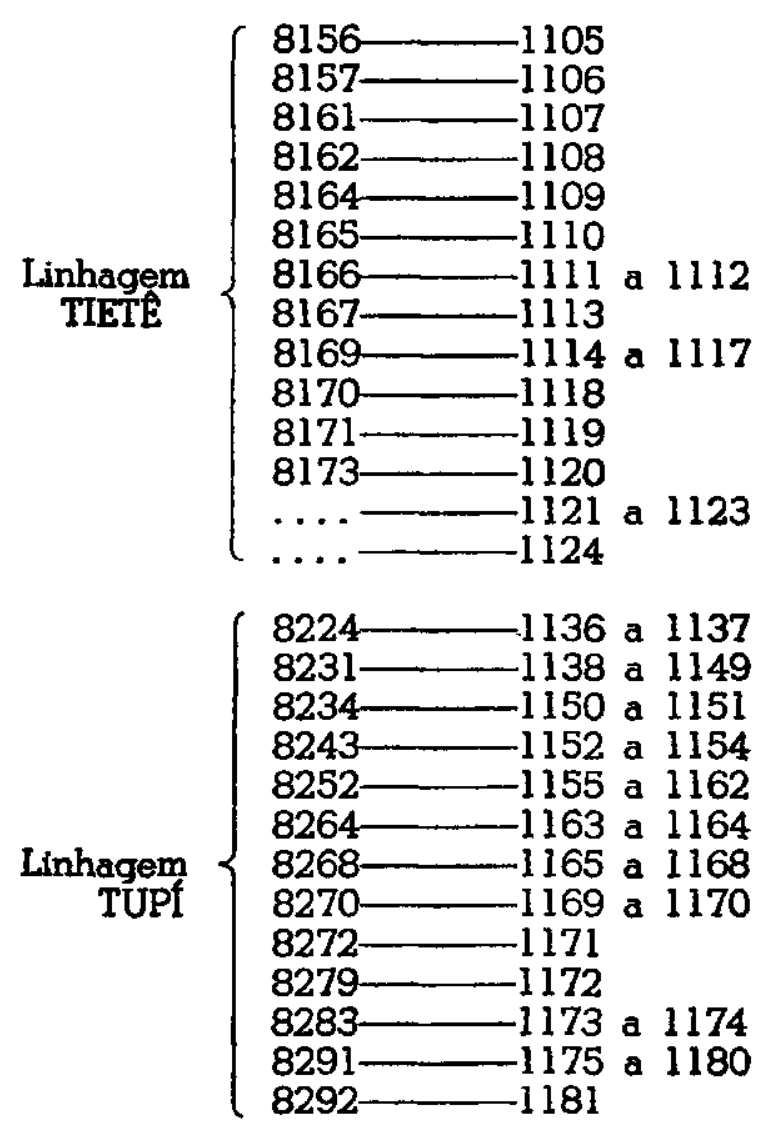

As 200 progênies finais foram o resultado de 4 autofecundações das melhores e mais promissoras plantas verificadas pelos recordes obtidos das medições efetuadas, pesagens das produções individuais, e capacidade de cada indivíduo em secar com coloração clara em estufa e eventualmente em galpão. A maioria das progênies pertencia à linhagem $612,1936-37$.

\section{O ENSAIO}

Foi transplantado em fevereiro de 1942 na Estação Experimental de Tietê, em terreno aparentemente uniforme, na ordem de sua numeração de registo, 1001 a 1199, 1941-42, em fileiras duplas, cada qual com 25 plantas, e espaçamento alternado 1,10 x 1,30 m entre fileiras, e $0,40 \mathrm{~m}$ entre plantas.

Entre cada 5 progênies foram intercaladas testemunhas, também com o mesmo número de plantas e em duas fileiras, as quais se distribuiram por todo o campo, em número de 39, destinando-se a permitir uma análise do terreno. As plantas componentes das testemunhas eram originárias de uma única planta autofecundada, e foram plantadas, medidas, tratadas, colhidas e curadas como se fôssem progênies. 


\section{ANÁLISE E APRECIAÇÃO DOS DADOS}

\section{I - Testemunhas}

Para fins de análise, as parcelas testemunha ou contrôle foram reunidas em fileiras e colunas, como indicado no quadro I. As fileiras e colunas representam as diagonais paralelas que ligam tôdas as testemunhas no campo. Assim, estas se distribuem em 12 colunas que, com exceção da primeira e última, contêm de 3 a 6 parcelas cada uma, e em 7 fileiras com 5 e 9, menos a primeira com uma e a última com 2 parcelas. Êste arranjo, embora permissível, tem o inconveniente de número variável de parcelas nas fileiras e colunas.

\section{QUADRO I}

DISPOSIÇAO DAS TESTEMUNHAS SEGUINDO AS LINHAS DIAGONAIS NO CAMPO

\begin{tabular}{|c|c|c|c|c|c|c|c|c|c|c|c|c|c|}
\hline \multirow{9}{*}{$\begin{array}{l}0 \\
4 \\
z \\
0 \\
a \\
0 \\
0\end{array}$} & \multicolumn{13}{|c|}{ FI L E I R A S } \\
\hline & & & & & 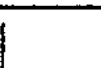 & 1 & & & & 1 & T-25 & & $\overline{1}$ \\
\hline & & & & & & & & T-14 & T.24 & T-26 & T-35 & T-36 & 5 \\
\hline & & & & $T-5$ & T-6 & T-13 & T-15 & $\mathrm{T}-23$ & T.27 & T-34 & T-37 & & 8 \\
\hline & & $\mathrm{T}-1$ & $\mathrm{~T}-4$ & T-7 & $\mathrm{T}-12$ & T-16 & T-22 & T-28 & T.33 & T-38 & & & 9 \\
\hline & T-2 & T-3 & T.8 & T-11 & T-17 & $\mathrm{T}-21$ & T-29 & $\mathrm{T}-32$ & T.39 & & & & 9 \\
\hline & & T-9 & T-10 & $\mathrm{T}-18$ & $\mathrm{~T}-20$ & T-30 & & & & & & & 5 \\
\hline & & & & T-19 & T-31 & & & & & & & & 2 \\
\hline & 1 & 3 & 3 & 5 & 5 & 4 & 3 & 4 & 4 & 3 & 3 & 1 & 39 \\
\hline
\end{tabular}

A avaliação da uniformidade ou homogeneidade do terreno foi efetuada pela análise dos seguintes dados: altura das plantas, número de fôlhas e seu comprimento e largura, e o índice - relação, largura sôbre o comprimento. Além dêsses, foi analisada a produção de cada parcela, em gramas, e o seu valor em cruzeiros (valor Cr.\$), isto é, o valor comercial das suas produções. Os valores fornecidos por parcela testemunha, para a análise, são as suas médias obtidas de 10 plantas sãs.

Os resultados da análise estatística constam no quadro II. Observamos uma heterogeneidade pronunciada com referência à produção, em gramas, ao seu valor $\mathrm{Cr} . \$$, e à altura das plantas. Quanto à produção, notamos (quadro III) que a única parcela da primeira fileira é bastante inferior às demais. A variação entre colunas, que é bastante grande, é de natureza desordenada, sendo a única parcela da última coluna 


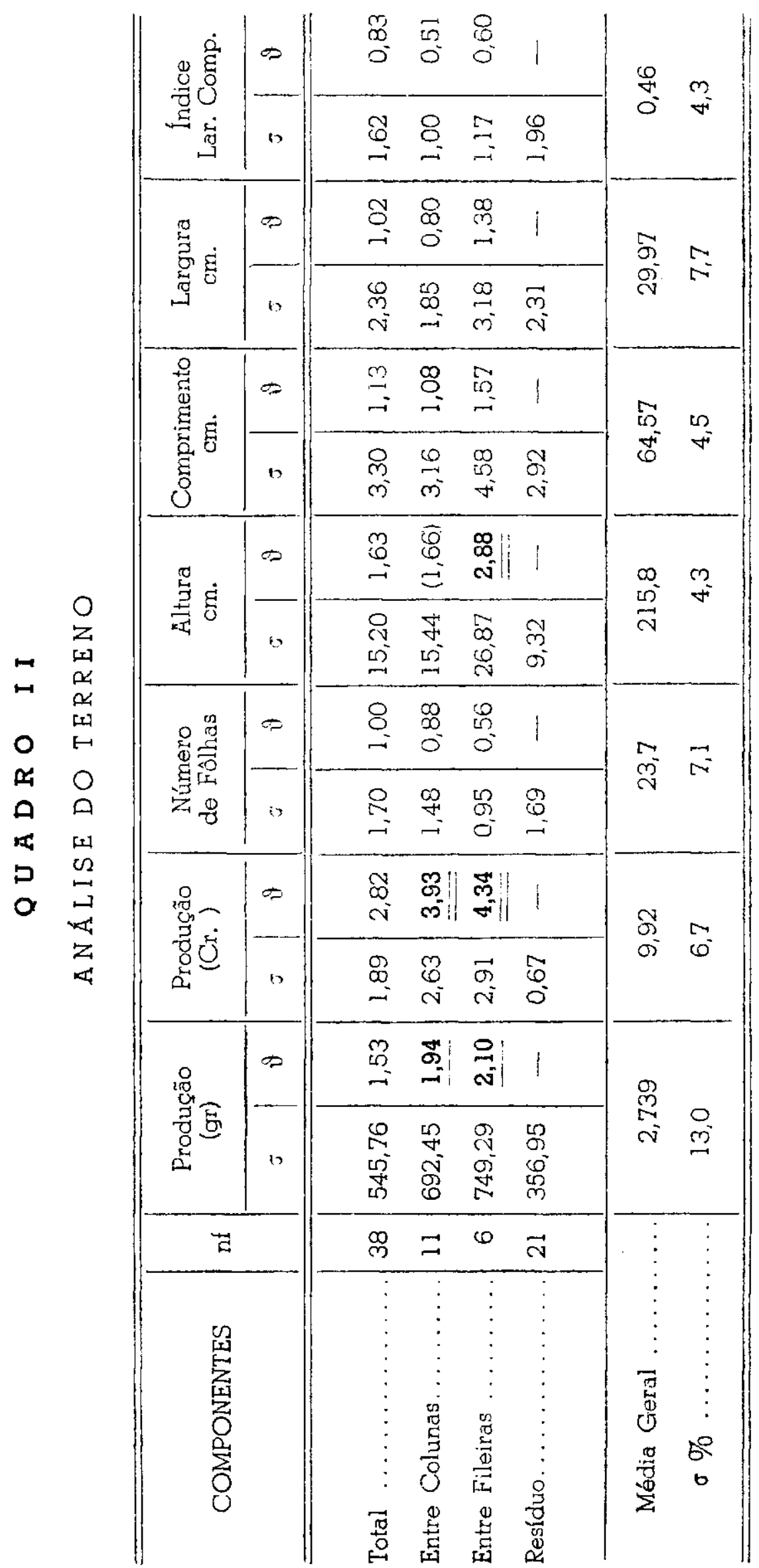


bem mais produtiva que tôdas as outras. As variações da altura das plantas demonstraram uma heterogeneidade no mesmo sentido, sendo também a única parcela da primeira fileira, muito inferior, e a única da última coluna, superior às demais.

De um modo geral, podemos considerar o terreno como razoàvelmente homogêneo.

\section{II -- Progênies}

\section{a) - MATERIAL DE ENSAIO -}

Como já vimos, consiste em 200 progênies descendentes de 5 linhagens oriundas da introdução V. 33. Estas 5 linhagens originaramse em 1936 e 1937, e sua descendência foi desde então mantida por autofecundação, como pode ser observado em seu registo de "pedigree". As famílias têm a denominação do ano de sua plantação, 38-39, 39-40, etc. Aquelas pertencentes ao ano 40-41 foram perdidas por anormalidades meteorológicas e moléstias, tendo sido plantadas de novo no ano seguinte. Desta maneira, a experiência foi retardada, mas não interrompida em sua continuidade. O material estudado é então composto de famílias que resultaram depois de 3 ou 4 autofecundações. Para podermos analisar os efeitos destas autofecundações, foram as progênies reunidas em grupos, de acôrdo com o seu "pedigree".

A comparação entre os valores, por parcela, da última autofecundação, dentro dos grupos indicados pela penúltima, foi considerada na análise estatística como a variação residual.

Para determinar se a homogeneidade aumentou com as autofecundações seguidas, foi aplicado um teste entre - dentro (quadro VII).

Do ponto de vista estatístico, o principal defeito metodológico consiste nas diferenças do número de parcelas, reunidas dentro dos grupos. Assim, cada uma das 5 linhagens é representada por um número diferente de variáveis. Entre essas cinco linhagens, há ainda uma diferença : as de número 569, 612 e 627 foram estudadas durante 4 anos seguidos, correspondendo a 4 autofecundações. Não perdendo de vista as complicações que podem ser causadas por esta heterogeneidade, parece-nos perfeitamente permissível prosseguir com a análise.

\section{b) - ANÁLISE DA PRODUÇ̃O (VALOR Cr. \$) -}

Foi tomado como base para a análise estatística o valor em cruzeiros atribuído à produção de cada parcela. Esta determinação de valor econômico foi feita pelo seguinte processo: as fôlhas foram curadas e classificadas de acôrdo com os 8 tipos comerciais em uso; o valor 


\section{QUADRO III}

MÉDIAS POR PARCELA TESTEMUNHA - PRODUÇAOO (gr)

\begin{tabular}{|c|c|c|c|c|c|c|c|c|c|c|c|c|c|}
\hline \multicolumn{13}{|c|}{ F I L E I R A S } & Média \\
\hline \multirow{7}{*}{ 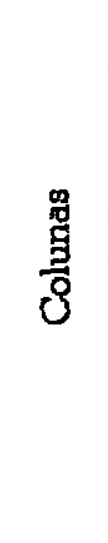 } & & & & & & & & & & & 1355 & & 1355 \\
\hline & & & & & & & & 2305 & 2520 & 2905 & 2720 & 4420 & 2974 \\
\hline & & & & 2075 & 3530 & 3230 & 3040 & 2625 & 3085 & 2910 & 3405 & & 2988 \\
\hline & & 2500 & 2225 & 3370 & 2985 & 3120 & 2450 & 2585 & 2840 & 3605 & & & 2853 \\
\hline & 2255 & 1905 & 2275 & 2910 & 2795 & 2750 & 2460 & 2850 & 3130 & & & & 2592 \\
\hline & & 2000 & 3075 & 2465 & 2445 & 2360 & & & & & & & 2469 \\
\hline & & & & 2930 & 2430 & & & & & & & & 2680 \\
\hline Média & 2255 & 2135 & 2525 & 2750 & 2837 & 2865 & 2650 & 2591 & 2894 & 3140 & 2493 & 4420 & 2739 \\
\hline
\end{tabular}

PRODUÇAO (Cr. \$)

\begin{tabular}{|c|c|c|c|c|c|c|c|c|c|c|c|c|c|}
\hline \multicolumn{13}{|c|}{ FILEIRAS } & Média \\
\hline \multirow{7}{*}{ 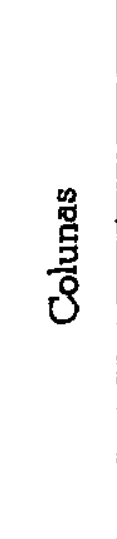 } & & & & & & & & & & & 5,1 & & 5,1 \\
\hline & & & & & & & & 9,1 & 9,5 & 11,8 & 9,3 & 15,6 & 11,1 \\
\hline & & & & 8,2 & 11,9 & 10,9 & 11,4 & 10,0 & 10,6 & 12,2 & 13,0 & & 11,0 \\
\hline & & 9,6 & 8,8 & 11,3 & 11,1 & 10,4 & 8,8 & 9,2 & 10,6 & 12,5 & & & 10,3 \\
\hline & 7,5 & 6,6 & 7,4 & 10,8 & 10,2 & 10,1 & 8,6 & 10,0 & 10,4 & & & & 9,1 \\
\hline & & 6,9 & 10,3 & 9,4 & 9,5 & 9,3 & & & & & & & 9,1 \\
\hline & & & 10,1 & 9,0 & & & & & & & & & 9,6 \\
\hline Média & 7,5 & 7,7 & 8,8 & 10,0 & 10,3 & 10,2 & 9,6 & 9,6 & 10,3 & 12,2 & 9,1 & 15,6 & 9,9 \\
\hline
\end{tabular}

ALTURA DAS PLANTAS

F I L E I R A S

Média

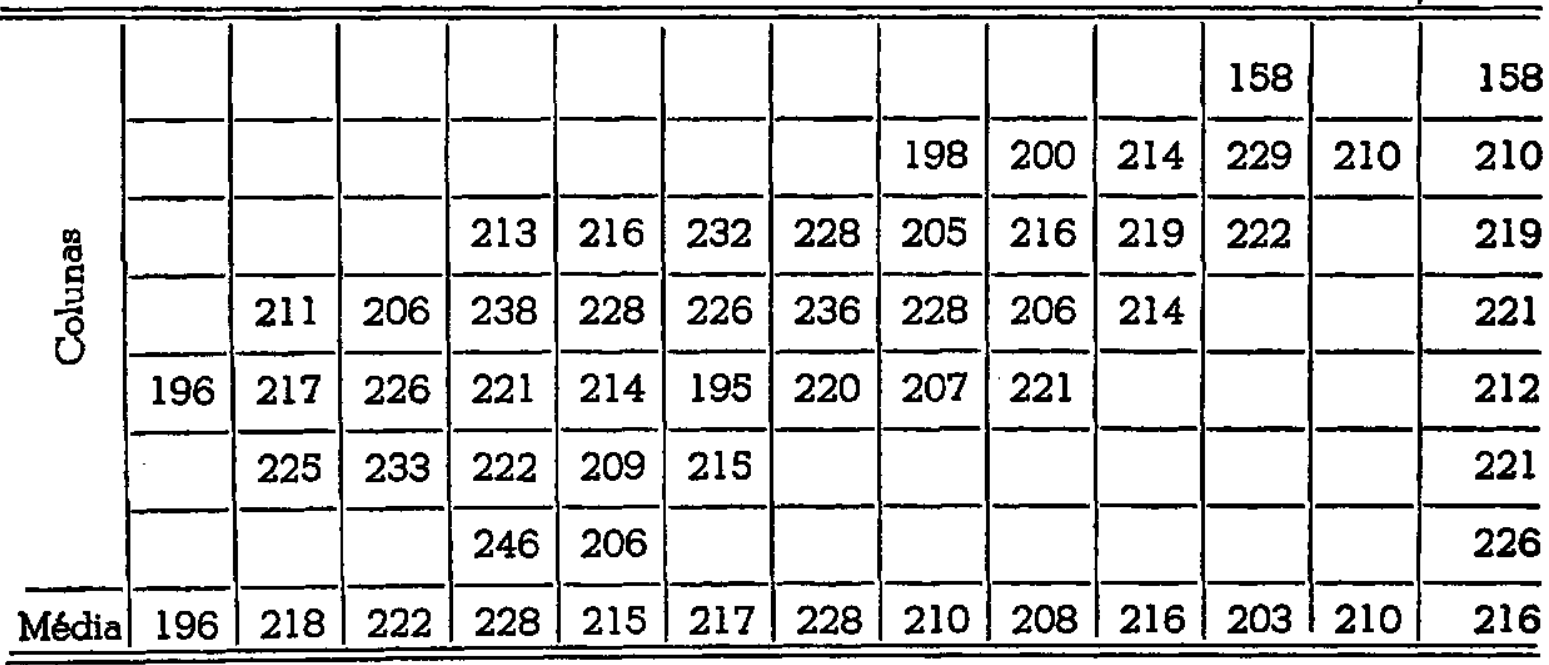


usado Cr. $\$$ é a soma dos produtos de cada um dos tipos pelo seu respectivo valor em cruzeiros.

É evidente que apenas as progênies derivadas da linhagem 612 são heterogêneas (quadro IV). Apareceu uma certa heterogeneidade na linhagem 569 depois da 2." autofecundação (1938-39). Sendo, porém, o êrro entre correspondente, da mesma ordem do terreno (quadro II), não nos parece necessário tomá-lo em especial consideração. Comparando-se os extremos nota-se que o valor real em $\mathrm{Cr} . \$$ é o dôbro.

Q U A D R O V

L I N H A E M 612

\begin{tabular}{c|r|r|r|r|r}
\hline $\mathbf{N}$ & $\mathbf{n}$ & $\overline{\mathbf{v}}$ & & & $\mathrm{t}(\mathrm{v}=90,02)$ \\
\hline \hline 723 & 21 & 11,27 & 0,34 & $+1,25$ & $\pm 3,67$ \\
722 & 35 & 1,02 & 0,27 & $\pm 1,00$ & $\pm 3,70$ \\
721 & 23 & 9,52 & 0,32 & $-0,50$ & $\pm 1,56$ \\
718 & 2 & 8,53 & 1,12 & 1,49 & $\pm 1,33$ \\
716 & 1 & 7,55 & 1,58 & 2,47 & $\pm 1,56$ \\
720 & 9 & 6,72 & 0,53 & 3,30 & $\pm 6,13$ \\
& 3 & 5,00 & 0,91 & 5,02 & $-5,52$ \\
\hline Total $\ldots . .$. & 94 & 10,02 & & & \\
\hline
\end{tabular}

Para se poder comparar as 5 linhagens entre si, foi feita uma análise conjunta, que consta no quadro VI. O êrro total foi decomposto apenas em 3 partes: entre as 5 linhagens, entre progênies obtidas por uma só autofecundação e o êrro residual que corresponde a tôdas as variações restantes. Esta última reunião é permitida, uma vez que os erros residuais para cada linhagem são da mesma ordem, como se pode ver pelo quadro IV.

A variação entre as progênies da primeira autofecundação é bastante significante e o seu valor elevado é ùnicamente provocado pela linhagem 612, já discutida.

A variação entre as linhagens é também significantemente grande. Estudando-se as 5 médias respectivas, do lado direito do quadro VI, pareceu-nos indicado fazer um agrupamento, juntando-se as linhagens "Tietê" e 627 num só grupo, sendo os seus valores pràticamente idênticos com a média de Cr.\$10,74 cruzeiros. Assim ficamos com 4 médias, tôdas elas diferindo em seu valor, de 70 centavos. Não pode haver nenhuma dúvida que as linhagens "Tietê" e 627 deram maior lucro que as demais. Quanto à linhagem 569, a inferioridade do seu valor é duvidosa. 


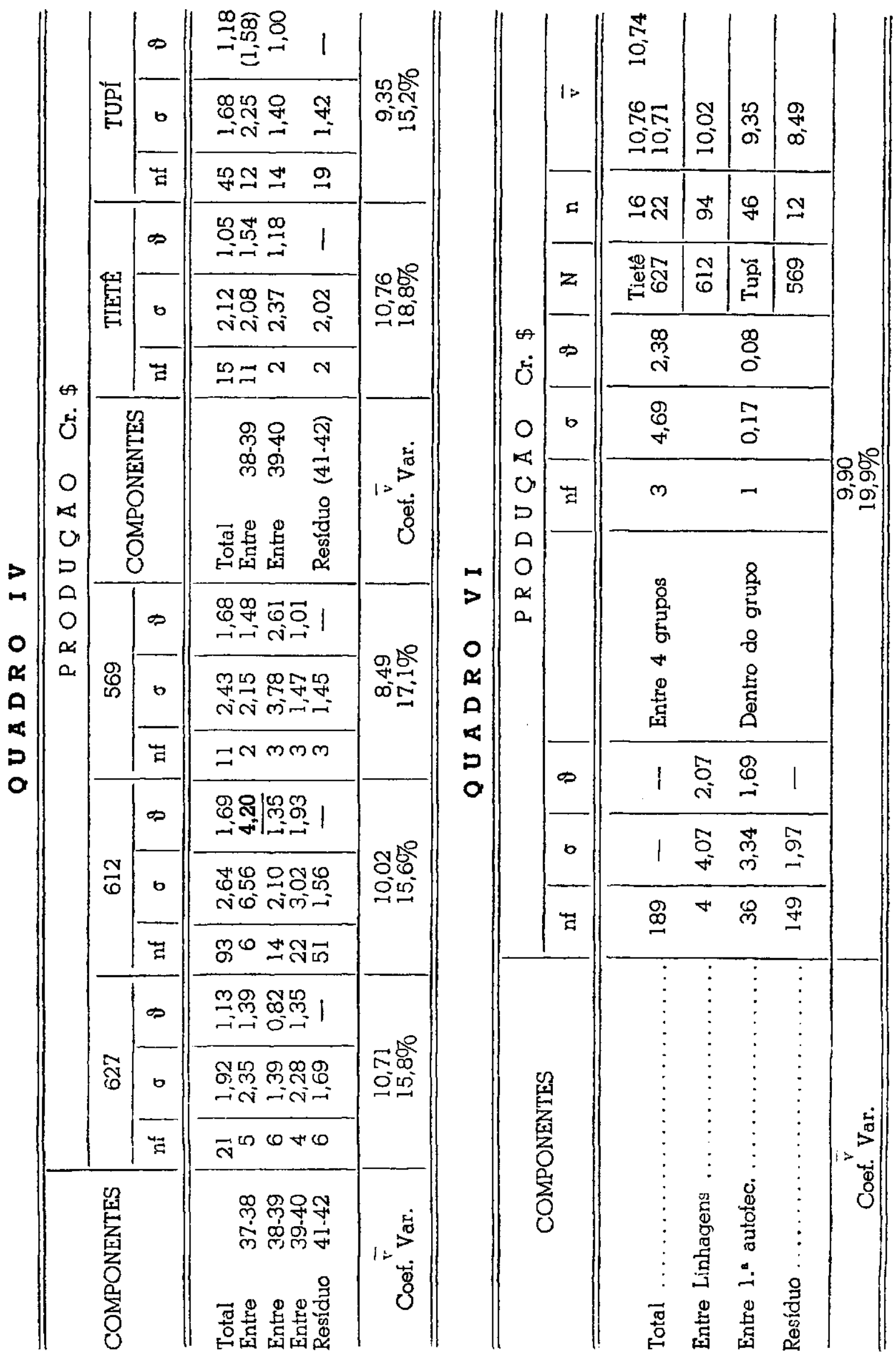




\section{c) - CARACTERES VEGETATIVOS -}

Os resultados que se referem às outras medições feitas se encontram reunidos no quadro VII: altura até a primeira cápsula ; número de fôlhas, exclusive as pequenas situadas na inflorescência; comprimento e largura, média das 5 fôlhas medianas. $O$ número de indivíduos para cada linhagem é agora menor do que antes, uma vez que não se pôde realizar medições em todos. A unidade da análise são as médias por parcela, médias estas obtidas das medições de mais ou menos 10 plantas em cada progênie.

A análise seguiu a marcha já indicada. O êrro total foi decomposto em 3 partes : 1) - entre as linhagens; 2) - entre os grupos de progênies obtidas depois da primeira autofecundação, dentro de cada linhagem; 3) - resíduo.

Inicialmente foi feita uma análise completa para cada linhagem, semelhante ao quadro I, mas, desta análise, só damos aquí os 5 casos que deram variações significantes.

Encontramos para a linhagem 612 (quadro VIII) uma heterogeneidade nas progênies obtidas na primeira autofecundação, com referência ao comprimento das fôlhas e índice, largura sôbre comprimento. Como se vê no quadro VIII, apesar da significância do quociente $\sigma \mathrm{E} / \sigma \mathrm{R}$, a variação atual das médias é de pouca importância. Um grupo de 5 progênies tem fôlhas em média de $64 \mathrm{~cm}$ de comprimento, enquanto um outro grupo de 2 progênies tem uma média de $67,5 \mathrm{~cm}$. O índice varia desordenadamente de 0,46 até 0,50.

$\mathrm{Na}$ linhagem "Tupí" (quadro IX) temos uma variação excessiva com referência ao comprimento e largura das fôlhas, $e$, conseqùentemente, também ao índice. Temos uma progênie com fôlhas de $58 \times 27 \mathrm{~cm}$ e outra com $68 \times 31 \mathrm{~cm}$. As restantes 5 progênies têm valores intermediários. $O$ índice varia desordenadamente de 0,42 até 0,50.

Com referência à decomposição geral (guadro VII), pode-se dizer que a variação de tamanho das fôlhas entre as progênies obtidas pela primeira autofecundação é relativamente de muito pouca monta. A variação, porém, entre as linhagens é bastante grande. Com referência a todos os caracteres, a linhagem 569 é a que mostra as maiores e mais numerosas fôlhas, mas as duas outras, que deram maior lucro, "Tietê" e 627, não the são muito inferiores, como se pode ver pelas médias dadas em baixo do quadro VII. 


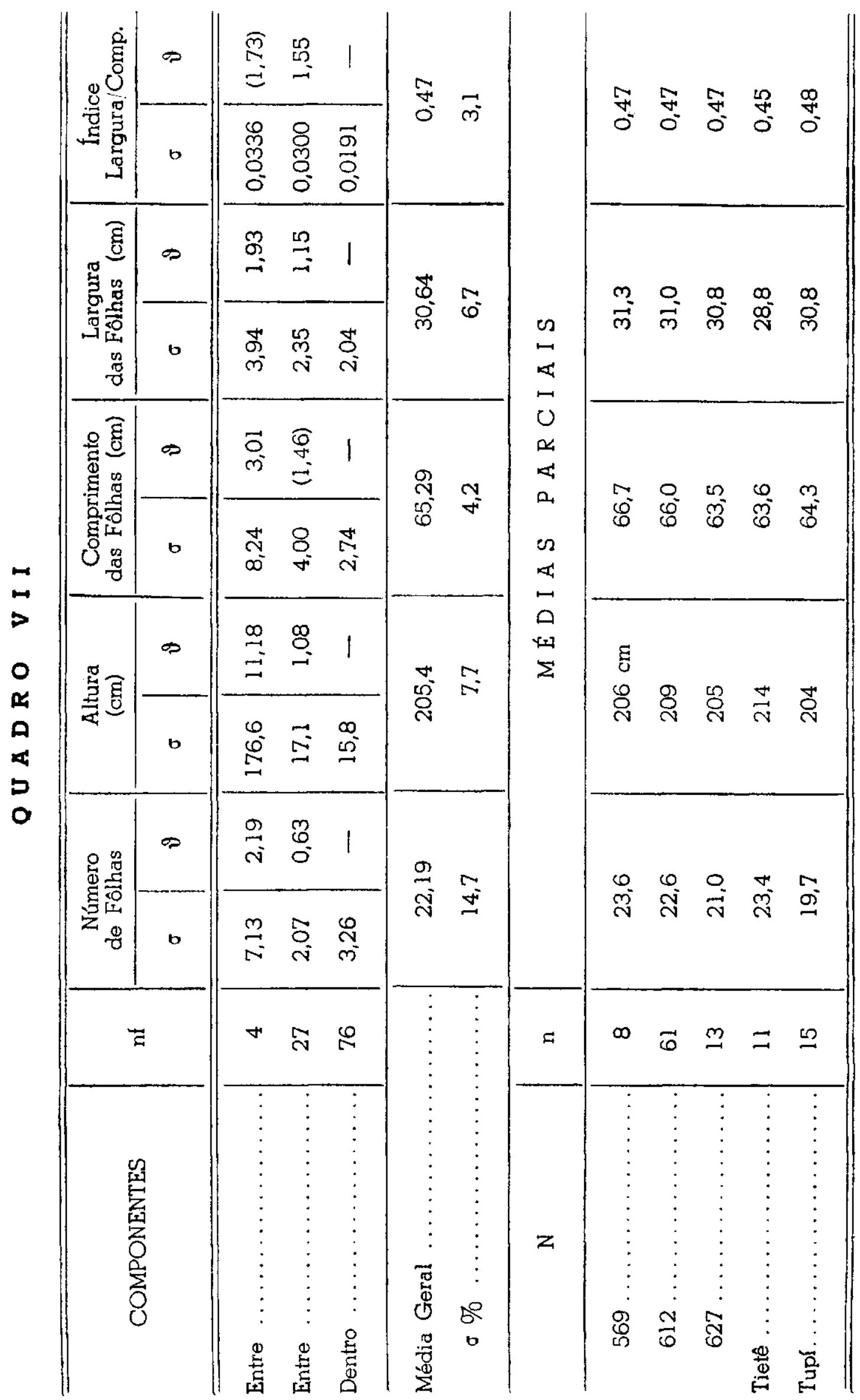




\section{Q U A D R O V I I I}

IINHAGEM 612

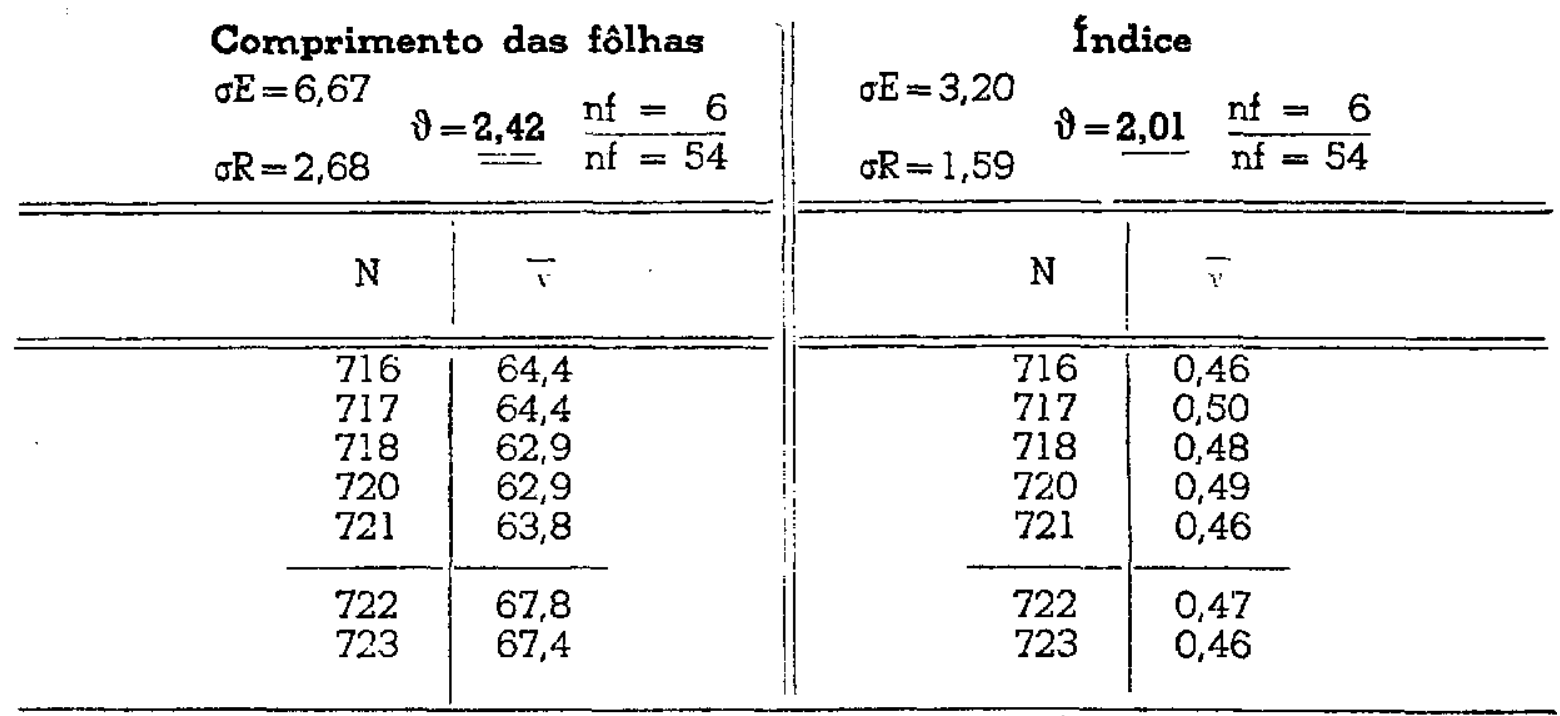

\section{Q U A D R O I X}

\section{TUPI}

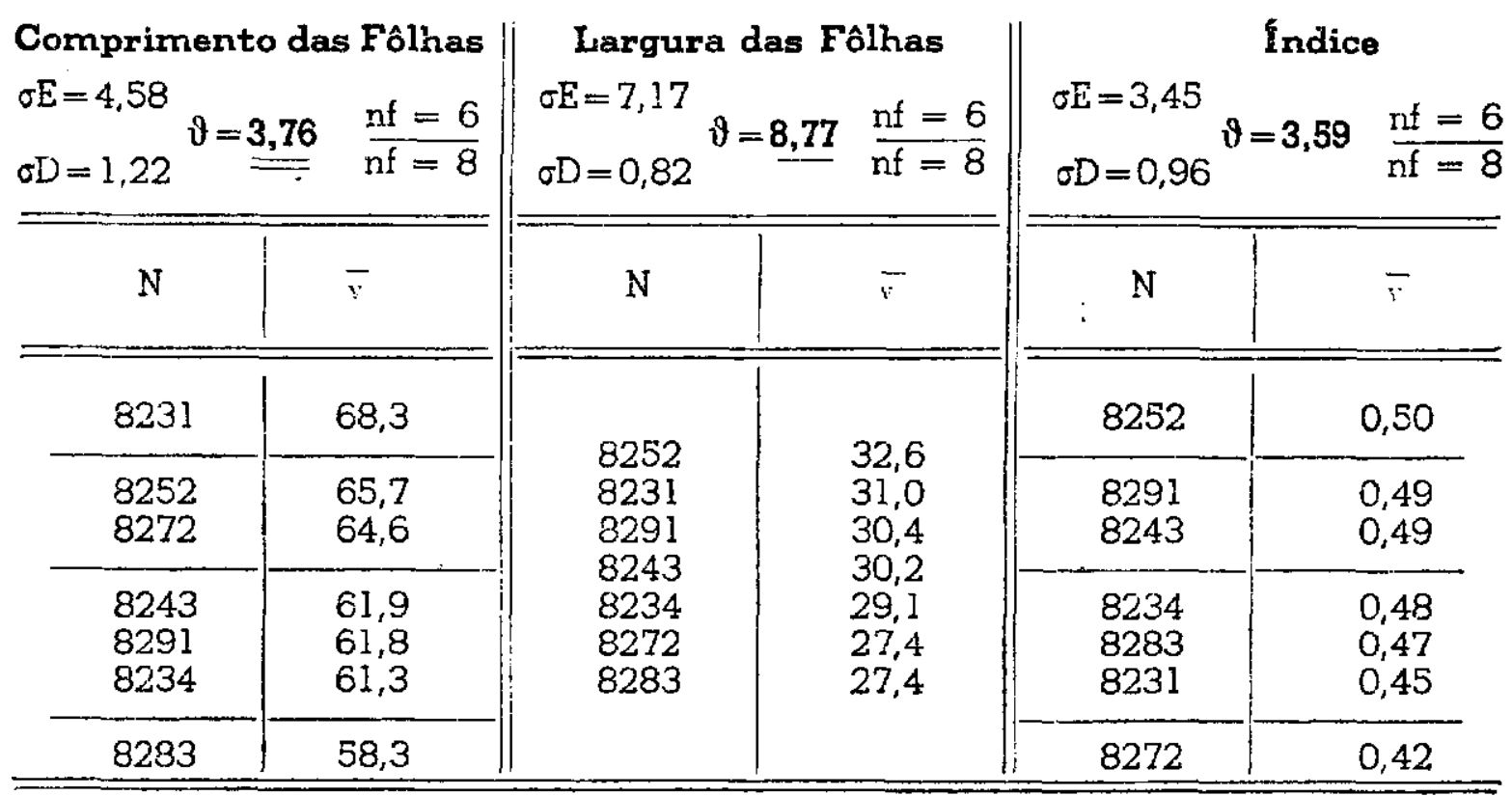

d) - CONCLUSÕES -

1. Efeito da seleção por autofecundação:

Foi encontrada, excefcionalmente, depois da primeira autofecundeç̃o, uma heterogeneidade com referência ao valor da produção, na linhagem 612, e nos caracteres das dimensc̃es das fôlhas na mesma 612 e tamkém na "Tupí".

Nas autofecundações subseqùentes não apareceu mais nenhuma het 
Parece ser indicado continuar o estudo da introdução 612, porém, apenas com as descendentes das famílias 722 e 723, que não sć deram maior lucro, como também possuiam fôlhas maiores.

Nas outras 4 linhagens não há diferenças de importância entre qualquer progênie.

A diferença entre as 5 linhagens estudadas é sempre bastante grande. De acôrdo com os caracteres aquí estudados, destaca-se como melhor a linhagem "Tietê", que dá maior lucro e tem fôlhas numerosas e grandes. Igualmente, mostram-se vantajosas, na linhagem 612, as descendentes das 2 famíitas 722 e 723, já acima indicadas. Também com o mesmo valor económico deve ser recomendada a 627, embora suas fôlhas sejam um tarito menores $e$ menos numerosas.

\section{Seleção entre plantas originais :}

De um modo geral, os dados obtidos estão de acôrdo com as conclusões alcançadas en outras séries experimentais sôbre o fumo Sumatra, e sôbre outras introduções de Amarelinho. A principal heterogeneidade, em todios os casos, existe entre as plantas eleitas da primeira geração, obtidas diretamente de sementes importadas. Pouca vantagem oferece a seleção depois de iniciada a autof́ecundação.

Esta conclusáo está também de acôrdo corn os nossos conhecimentos sôbre a biolcgia do florescimerito de Nicotiana tabacum, espécie que se propaga quase exclusivamente por autofecundação.

Assim, devemos considerar as sementes importadas e não selecionadas como representando uma população heterogênea, quando cada indivíduo é pràticamente um homoziçoto. A sua descendência, obtida por autofecundação, é essencialmente uma linha pura.

\section{Material para seleção:}

Para têrmos mais ampio material para a seleção, devemos usar dois caminhos: podemos selecionar o maicr número possível de plantas diferentes, e obtidas das sementes importadas, autofecundando-as. Depois comparamos as numerosas progênies assim obtidas, após uma só autofecundação, eliminando as inferiores.

$O$ outro caminho consiste em provocar heterogeneidade pelo cruzamento de diferentes indivíduos e selecionar a partir de $2 .{ }^{a}$ geração. Esste último processo, que é bem lento e laborioso até que se chegue finalmente de novo a linhas puras, não nos parece, por isso, na prática, muito vantajoso, uma vez que se encontram, entre as plantas das impor- 
tações originais, indivíduos com os caraterísticos desejáveis, já em combinação.

\section{Conclusôes finais :}

Devemos lembrar mais um outro fator importante: as nossas conclusões sôbre as melhores linhagens necessitam de uma certa reserva. Foram incluídas, nas comparações, progênies plantadas no mesmo dia e cultivadas sob idênticas condições. Sabemos, pelas nossas experiências sôbre época de plantio, que pequenas variações na época de transplante provocam variações consideráveis, e que nem todos os tipos de fumo reagem de maneira idêntica. É assim necessário esclarecer que as comparações entre linhagens, nas quais baseamos nossas conclusões, foram feitas na época que consideramos mais favorável, e, portanto, poderão ser aceitas para todo o Estado, menos talvez, para as zonas climatèricamente muito diferentes, como a do litoral ou ainda a da Mantiqueira. 


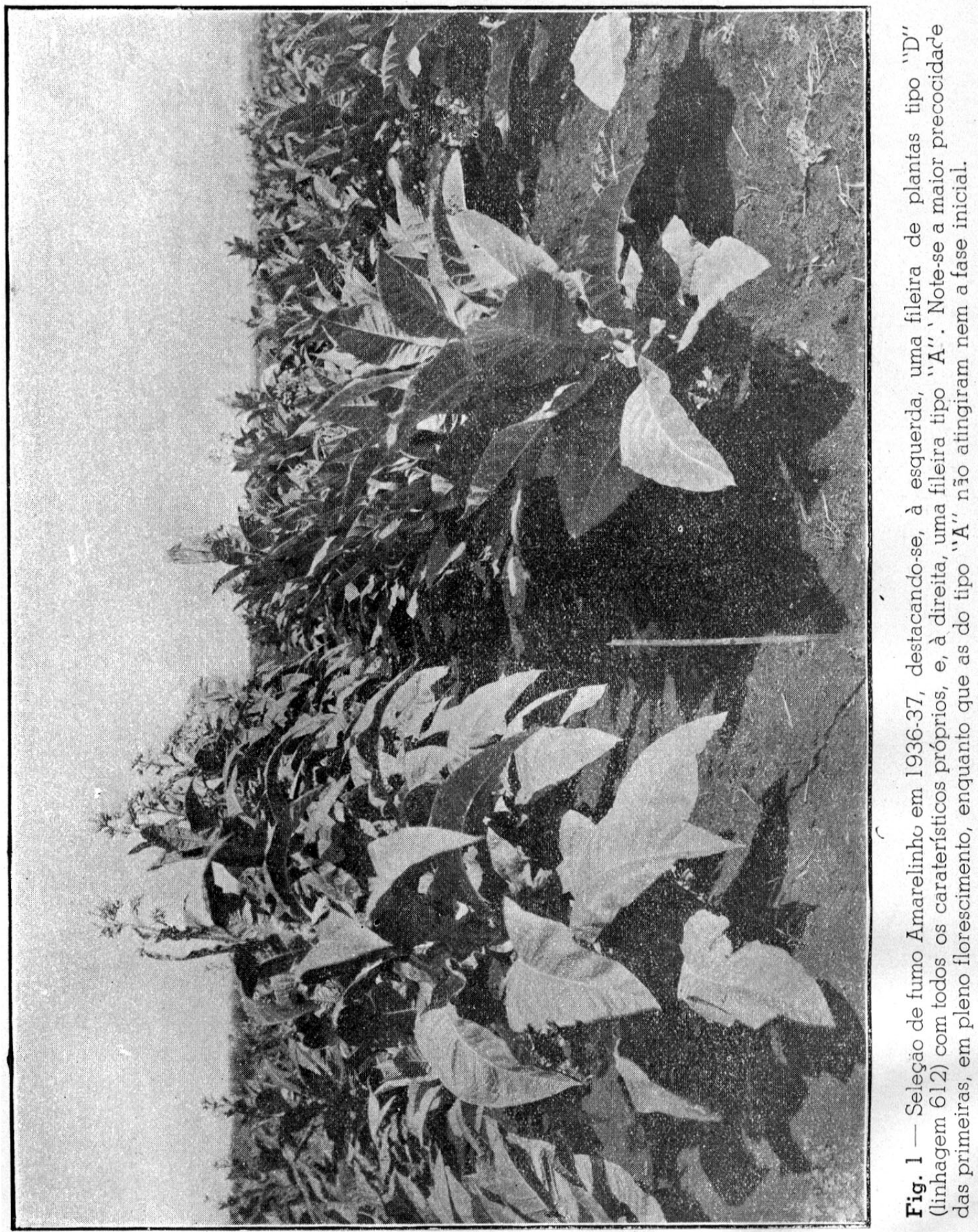



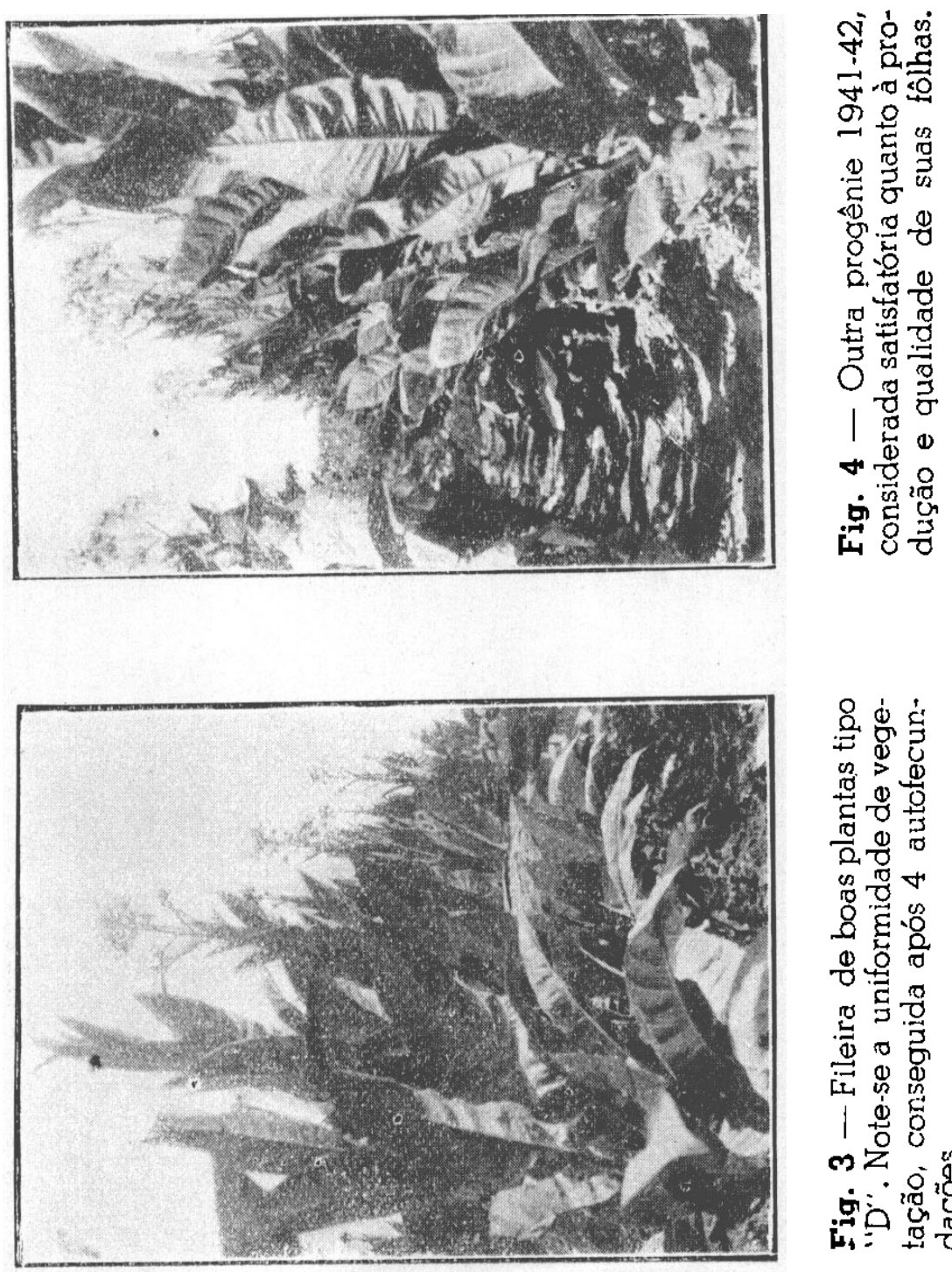

엻 i⿱ $)$

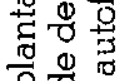

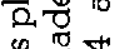
要势

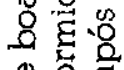
هั? ช

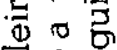

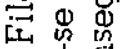

$1 \stackrel{0}{0}$ ल之

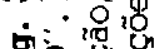

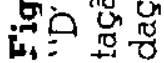

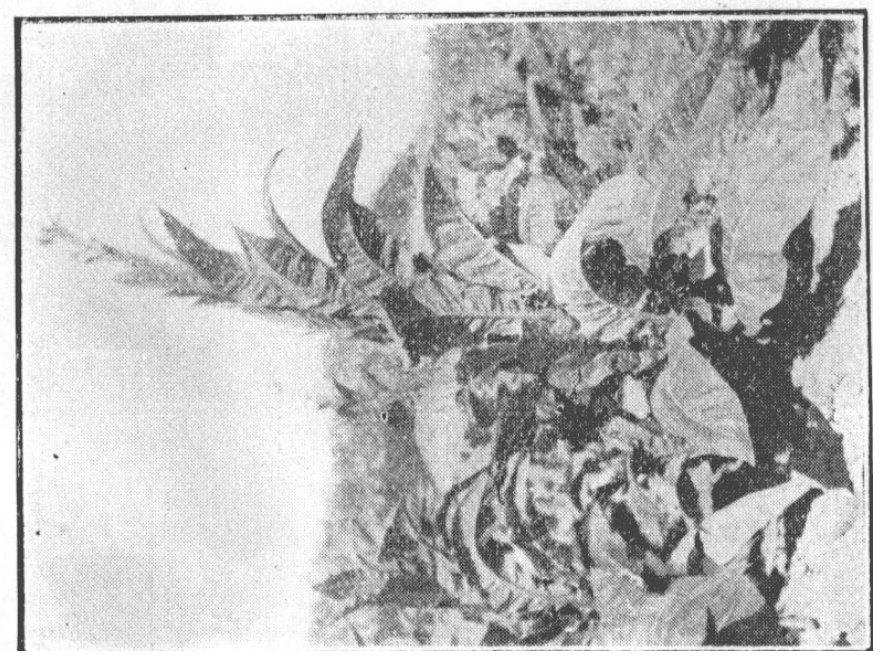

ᄋ్ల

$>=\frac{8}{0}$

ช

苍 $=\frac{0}{0}$ 要方

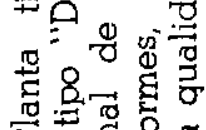

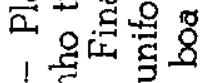
। ง

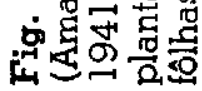

